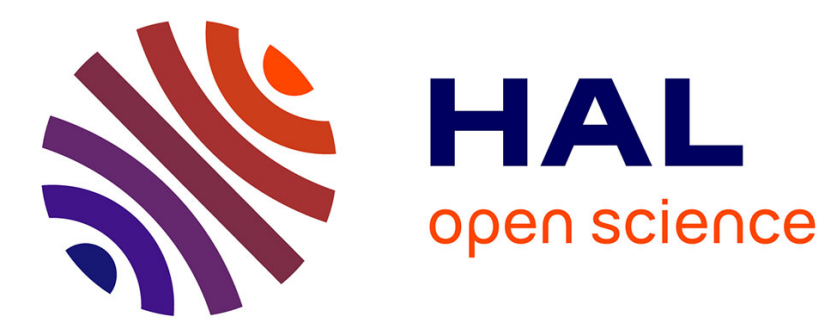

\title{
GIS-Oriented Lifecycle Management for Sustainability
}

Kiyan Vadoudi, Florian Bratec, Nadège Troussier

\section{To cite this version:}

Kiyan Vadoudi, Florian Bratec, Nadège Troussier. GIS-Oriented Lifecycle Management for Sustainability. 13th IFIP International Conference on Product Lifecycle Management (PLM), Jul 2016, Columbia, SC, United States. pp.248-258, 10.1007/978-3-319-54660-5_23 . hal-01699673

\section{HAL Id: hal-01699673 \\ https://hal.inria.fr/hal-01699673}

Submitted on 2 Feb 2018

HAL is a multi-disciplinary open access archive for the deposit and dissemination of scientific research documents, whether they are published or not. The documents may come from teaching and research institutions in France or abroad, or from public or private research centers.
L'archive ouverte pluridisciplinaire HAL, est destinée au dépôt et à la diffusion de documents scientifiques de niveau recherche, publiés ou non, émanant des établissements d'enseignement et de recherche français ou étrangers, des laboratoires publics ou privés. 


\title{
GIS-oriented lifecycle management for sustainability
}

\author{
Kiyan Vadoudi*, Florian Bratec, Nadège Troussier \\ ICD, HETIC Department, CREIDD, Université de technologie de Troyes, UMR 6281, \\ CNRS, Troyes, France \\ kiyan.vadoudi@utt.fr
}

\begin{abstract}
Studying a product's environmental impact on an interacted territory's environmental status before and after design can increase decision makers' accuracy when considering design for sustainability. Spatial representation of environmental information using Geographic Information Systems (GIS) is an approach to analyzing environmental status. This paper proposes a new data model to integrate geospatial data with product related data through environmental impacts over the whole lifecycle. This model uses coupling of GIS and PLM by ontology building. This new data model offers the possibility of enhancing sustainable products and obtaining more relevant results due to higher site specificity.
\end{abstract}

Keywords: Product lifecycle management, Geographical information system, Life Cycle Assessment, Ontology, Regionalization

\section{Introduction}

Product lifecycle management (PLM) is defined as the integrated management of product related information through the entire product lifecycle [1]. Recently, some studies on general capabilities of PLM to improve sustainability paradigm have been presented [2, 3], but the subject is still not solved completely. PLM for Design for Sustainability (DfS) involves several challenges and one of these is the lack of information for decision makers. Integration of software tools like Life Cycle Assessment (LCA) in support of DfS could be a solution. In the LCA framework [4], Life Cycle Inventory (LCI) consists of a model of the product system, its location (the technosphere and ecosphere) and a quantification of elementary flows. Then Life Cycle Impact Assessment (LCIA) looks at the fate of the substances and at the potential impacts of the intervention between the product system and the ecosphere [5]. Technological and environmental aspects are not independent and a change in the environmental setting implicitly needs a change in the technology used. As the characteristics and environmental status of ecospheres differ territorially, design characteristics and specifications of technologies need to be modified and adopted based on these differences, but we lack knowledge of how these features really would change design choices. Implementation of this approach in product and system design will require geospatial information about related ecosphere(s), but current models of product design do not include the support for geographical information. 
This paper aims at answering this problem by modeling the link between territory and PLM/LCA using a GIS/PLM/LCA framework. Firstly, it proposes a new product data model consisting of product data, environmental data, such as LCI, and geographical data about the environmental status of territory. This proposed model provides new design information for decision makers. Then, we discuss a case study: how this new information could change decisions in order to design for sustainability. Finally, we conclude with future works.

\section{State of the art on tools to support design for sustainability}

Nowadays, sustainable development becomes more and more complex and knowledge intensive, requiring additional supports and assistance, especially in the early design stages. The intelligent use of existing digital databases like PLM could help to solve the problem. PLM enables the comparison, evaluation and optimization of the different product requirements, linking production information to design through the entire lifecycle. To succeed in the mission of supporting PLM, applications need reliable, complete and efficient data models to be able to filter, structure, integrate, control and channel flows of information.

In 2002 S. J. Fenves et al. proposed the core product model (CPM) to support the full range of product lifecycle management (PLM) [6]. Gujarathi et al. [7] developed a common data model (CDM) containing all required parametric information for both $\mathrm{CAD}$ modeling and $\mathrm{CAE}$ analysis for $\mathrm{CAD} / \mathrm{CAE}$ parametric integration. Recently Utpal et al. [8] developed an Integrated Product Information Model (IPIM) based on CPM in the context of sustainable design and manufacturing. Although MML, CPM, CDM and IPIM are used to extract and model the knowledge applied in technological systems, none of them are able to create a data list that can be used for sustainable design, especially from environmental aspect.

Since LCA have been developed to support DfS [9], but seems difficult to apply it in the early stages of design, because most of the existing tools based on LCA do not focus on design and they are set for a strategic management or a retrospective analysis of existing products. A real LCA can only be correctly used for a completely defined product where data about lifecycle are available and accurate. Regionalization is used as a solution to improve the accuracy of life cycle assessment (LCA) results and make it more relevant for decision makers. There has been a growing body of regionalized LCA research, and in particular many regionalized LCA models coupled with Geographical Information System (GIS) have been developed for agricultural products [10-13]. However, insufficient attention has been paid to industrial products, in terms of their regionalized life cycle inventory (LCI), the study of the related geographic location and status of environmental impacts before and after proposed design for each step of lifecycle. GIS has been used by several authors to integrate spatial differentiation in LCA, not only for the calculation of regionalized characterization factors but also for creating site-specific inventories and matching each of these [13, 14]. GIS, by accessing different sources of information (biological resources, pollution sources and affected areas, land cover and use, water availability and quality and energy sources and use), enables the use of a set of simple operations 
such as overlay, classification, interpolation and aggregation of spatial information [10] that could generate useful information for decision makers in support of DfS. In the next section a data model is proposed, which integrates GIS with environmental inventory (LCI) and product (CPM) data models.

\section{Proposed data model (PEG)}

This proposed conceptual model (Fig.1) contains three sub data models, namely, product $(\mathrm{P})$, environment impact $(\mathrm{E})$ and geography $(\mathrm{G})$.

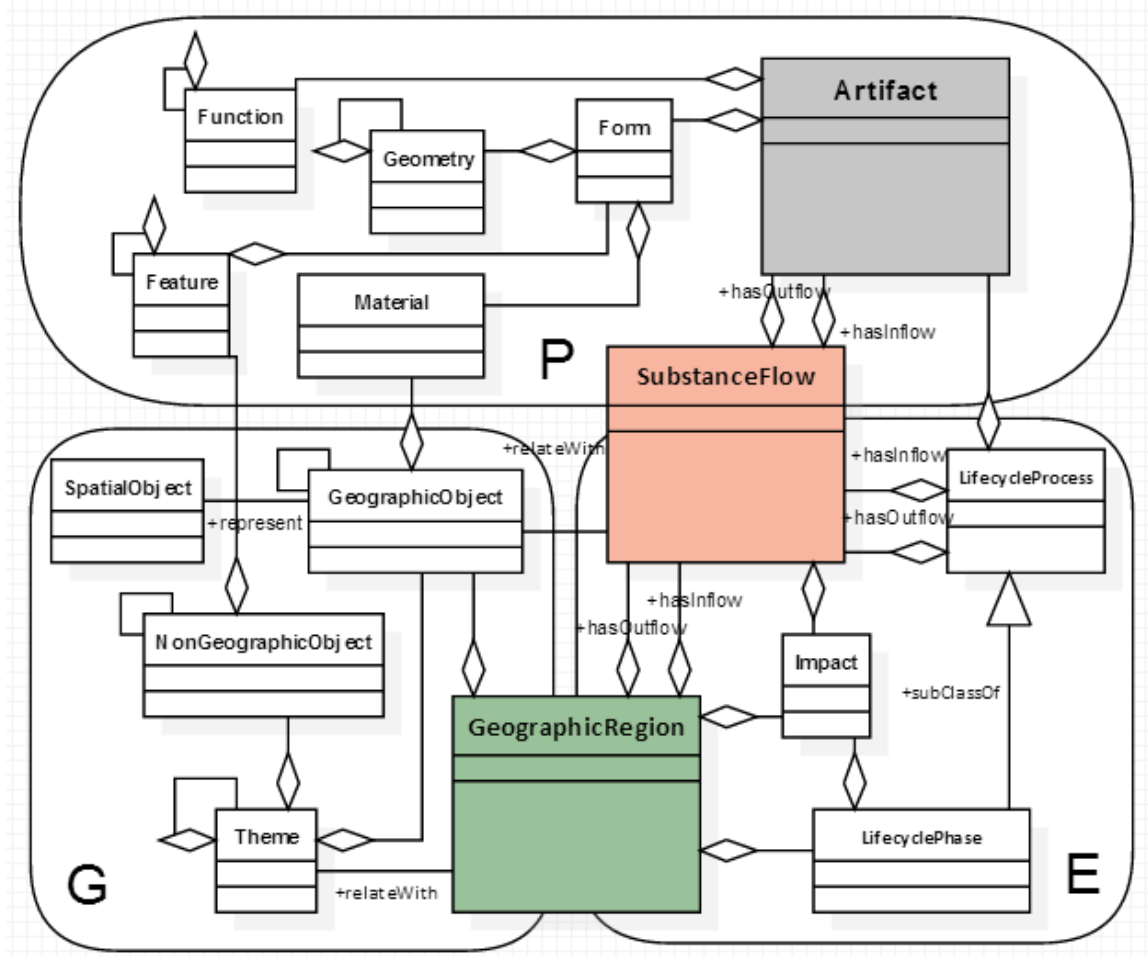

Fig. 1. PEG data model

'Artifact' is the main class of category (P), shown in grey. This class has relationships with category (E) through LifecycleProcess and SubstanceFlow classes. SubstanceFlow class, shown in red, is the main class of category (E) and a link between Artifact and GeographicRegion classes. Each one of these subsections are described in more detail below. 


\subsection{Product data model (P)}

Data models and ontologies have been built to represent various engineering fields and product lifecycle stages in different categories. The knowledge models and ontologies focus on the product [6,15-19], on the process [20-22], on the productprocess [23-25] and etc. In the models on product category, many researchers based their works on NIST's core product model (CPM) because it is a base-level product model: generic, simple, open, non-proprietary, extensible and independent of any specific product development. Moreover, CPM capable of capturing engineering context commonly shared in product development activities, this makes it capable of supporting the full range of product lifecycle management (PLM) [26]. We will base category (P) on combining the advantages of CPM with our proposed goal of designing a manufactured product: Form, Geometry, Function, Material, Feature and Artifact classes are selected due to their strong relation with geographical and environment features.

\subsection{Environmental impact data model (E)}

The first LCA ontology project was designed under Project CASCADE [27]. Bertin et al.[28] presented a semantic approach to LCA knowledge in 2012 which it is applied to energy environmental impact data management. In 2015 Yingzhong et al. [5] proposed an LCA-oriented semantic concept model for the product life cycle by dividing the environmental space of the product into technosphere and ecosphere. And recently Akkharawoot et al. [29] described a collaborative approach to ontology development for data qualification for life cycle assessment by taking into consideration the Life Cycle Inventory (LCI) and Data Quality Indicator (DQI). Part (E) of our model is based on a modified version of the model by Yingzhong et al. [5] due to its concentration on lifecycle view. In this semantic concept model, three toplevel classes are defined: Product_Lifecycle class; Lifecycle_Process class and Substance_flow class. Substance_flow Class as a base of flow ontology is divided into three subclasses: Elementary_Flows class; Product_Flows class and Waste_Flows class. Elementary flows as the basis for calculating environmental impacts of a product life cycle can be classified into two further subclasses: Resources and Emissions classes.

\subsection{Geography data model (G)}

Geographical database modeling has been followed by different conceptual data models such as GeoOOA [30], Geo-ER [31], Geo-OMT [32], MADS [33] and GeoFrame [34]. Another study was carried out by Pedersen and Tryfona [35], who present a formal definition of a data model for a Geographical Data Warehouse (GDW) at the conceptual level. More recently, Malinowski and Zimanyi [36] presented a GDW data model based on the MADS model, which is, in turn, an objectbased entity-relationship approach. Zghal etal. [53] propose a meta model based on 
the UML class diagram which addresses spatial dimensions, spatial hierarchies and spatial measures. From the mentioned data models, GeoFrame [34] is selected as (G) due to its ability to include pattern analysis which facilitates use of geographical data for designers from different backgrounds with little knowledge of software development methods. In this framework there are three main classes: Geographic_Region; Theme; Nongeographic_Object. Theme defines during conceptual design which can lead to the implementation of several layers. Geographic_Object class is a generalization for all classes of the domain that are perceived in the object view. The attributes defined in the class are mapped as rational table field. Geographic_Region Class can be defined by physical characteristics, human characteristics, and functional characteristics.

PEG model could provide the following information: (1) mapping the environmental impacts of designed product on interacted territory, defining specified design parameters like the materials (The materials thus chosen must be analyzed to satisfy the design form, overall production feasibility and especially the environmental impacts); (2) finding patterns for environmental impacts by comparing different maps which help to predict the environmental status of territory; (3) taking into account environmental condition of territory in product and system design which could lead to have changes in design specifications.

\section{Case study}

The lifecycle of a flashlight, which is a simple manufacturing product, is provided to illustrate the new kind information supported by proposed model (Fig.1). A simple flashlight consists of two main components: Body and head. The head contains the cap, lamp, lamp holder, lens and reflector, which is connected to the body including tail cap, spring, connector, on/off switch, brass slide and plastic shell which holds the battery. Using BOM information and the manufacturing process planning of the product, a manufacturing process tree can be obtained, combining the specific information of the materials used to make the parts, and the manufacturing unit process information. Because of the page limitation for submission processes of the conference, lifecycle is limited to manufacturing and end of life (EOL) processes (LifecycleProcess, LifecyclePhase) of plastic shell (Artifact \& GeographiObject). The manufacturing phase of the plastic shell consists of manufacturing unit processes (gate to gate), which converts the polypropylene material by an injection process into a final shell product and the EOL consist collection and recycling process of plastic and also electrical parts (battery and lamp). For LCA study of this case, SO2 (SubstanceFlow \& GeographiObject) is the only emission studied and included as GIS data. Champagne Ardenne in France (GeographicRegion) is considered as the geographical region where all up-stream process of electricity (SubstanceFlow \& NonGeographiObject) and material productions (SubstanceFlow, Material, LifecyclePhase \& GeographiObject) are located.

Elementary flow data as part of substance flow related to the manufacturing and EOL of this part is collected and used to create the flow instances. The other flows are sets of continuous production processes to produce materials and energy (cradle to 
grave), including polypropylene production, electricity production, etc. LCI data about the amount of SO2 emission for production processes is obtained from open source software OpenLCA [37] and ELCD database [38]. For example, the injection process consumes electricity so the power consumption can be defined as the reference flow and input into the LCI database to obtain the environmental impact of all upstream processes of the electricity supply production. Fig.2 illustrates a semantic presentation for the part of the data model mentioned to tag the process instances, the flow instances and geographic regions instances. For example, the first node is polypropylene material, result of the "Polymer_Production" shown as class "Material_1". The geographical production location of the polymer is in Champagne Ardenne, referenced as " $\mathrm{R} \_1$ " class which could be presented as a geographical object on the map as a part of up-stream process. Moreover, this class could also be named as the elementary flow/polymer producer/raw material/ etc layers. Polymer production needs electrical energy ("Energt_1" class) produced in another geographical location of same region ("class R_2"). "Injection_process_1" is part of the manufacturing process, and "SO2_3" is an instance of the Air_Emission class and its substance name is SO2, which is an instance of "GeoObject" enters entered geographic region $\mathrm{R} \_3$.

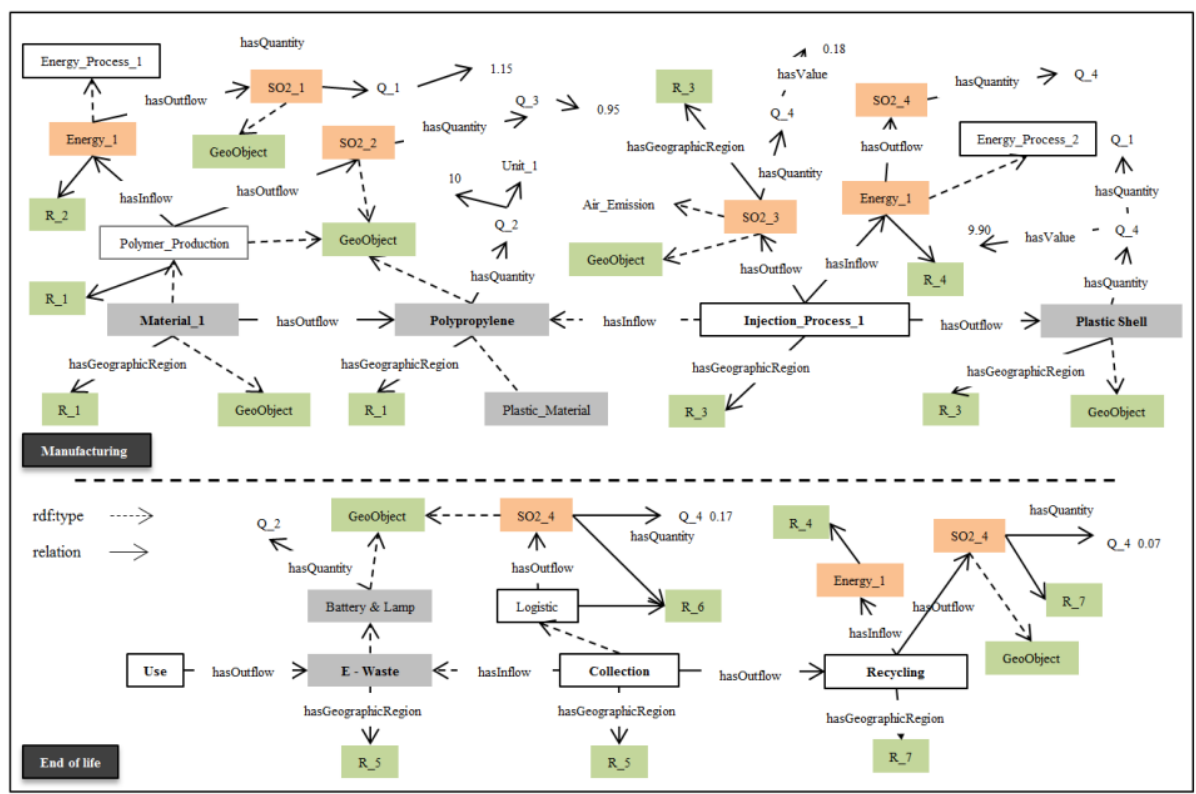

Fig. 2. Illustration of proposed data model for plastic shell production and end of life processes

There are two approaches [39] to collecting E-wastes in France; individuals deliver e-waste to collection points inside cities and the second approach involves producers or individuals using out-of-town recovery centers. The first approach is selected as EOL process for this case study. Batteries and lamps ("E-waste class") is the result of outflow from use stage which has inflow to collection points (R_5). After collection, there is logistic process to deliver wastes into recycling centers ( $R_{-}$7). 
Fig.3 presents SO2 emission for different geographical locations as GIS data layers. Map1, Map2 and Map3 are divided maps of each activity's impact and Total map is the $\mathrm{SO} 2$ emission of the total manufacturing process with its logistics etc.

In LCA, there are several data formats to describe environmental information. The most common among these are EcoSpold1, EcoSpold2 and ILCD and are based on the extended markup language XML [40]. In GIS there are two different approaches to represent geospatial information. The first approach is raster-based and uses formats derived from web-design (GeoTIFF, IMG, JPEG2000, etc) [41]. The second approach is vector-based and is more commonly used today. Many formats can link information with coordinates using vectors, and the most popular are the GPS exchange format (GPX), the keyhole markup language (KML) and the geography markup language (GML) [42].
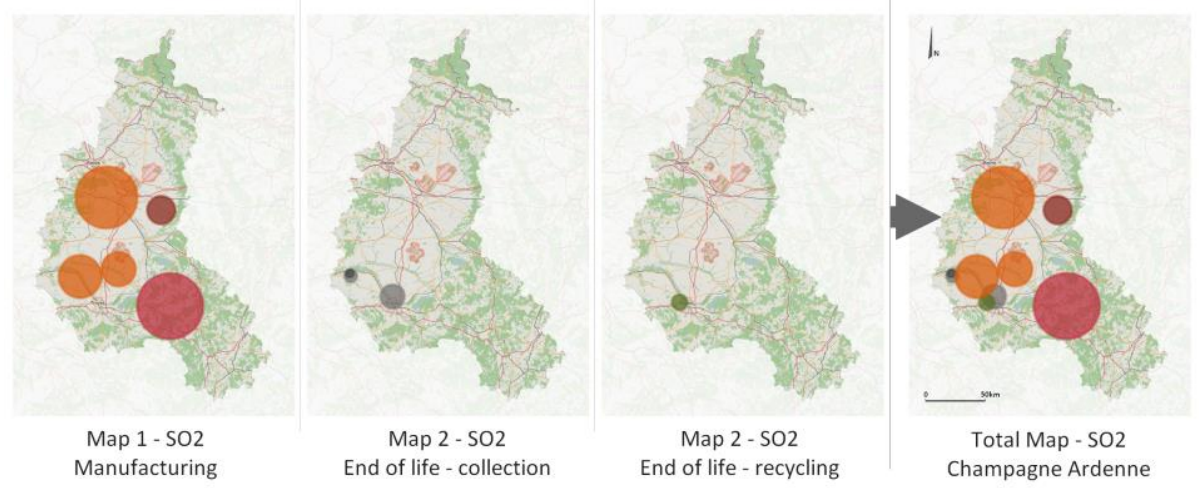

Fig. 3. SO2 emissions in different geographical location of manufacturing and EOL processes

Considering the multiple existing formats to describe environmental and geospatial information, there are many ways to combine the data. However, there is still no format that allows data from LCA and data from GIS to be stored in the same file. To create the maps shown in Figure 3, a PostgreSQL database was chosen to store the data and to make it available with the same system of language requests (SQL). On one hand, the ILCD format (based on XML) had to be covered in a relational data model to be included as SQL data tables. On the other hand, the PostgreSQL structure allowed us to link the LCA data with geospatial information: coordinates and geometrical objects (points in this case but it could also admit lines and polygons). The resulting data model, coupled to the JavaScript library OpenLayers permitted the LCA results to be displayed on a base map form MapQuest.

\section{Discussion and conclusion}

The above analysis and results show that the proposed model and its semantic representation by case study can represent the interactions between the product and its territory and the quantized impacts on the environment and consumption for the resources within a product life cycle. Flow instances can be determined and presented 
as specific geographical features by different GIS data layers. Access to GIS layers can help product designers to analysis the environmental impacts before and after design, which may change design characteristics and product specifications based on the environmental status of each territory. Using the proposed model, it will be possible to include geographical characteristics for environmental impact assessment and provide them to designers helping them to identify which product characteristics and specifications are the source of an impact in order to lead to better design for sustainability solutions Finally, as shown in fig.4, this approach can solve the problem of LCA which is not applicable in the early stages of design.
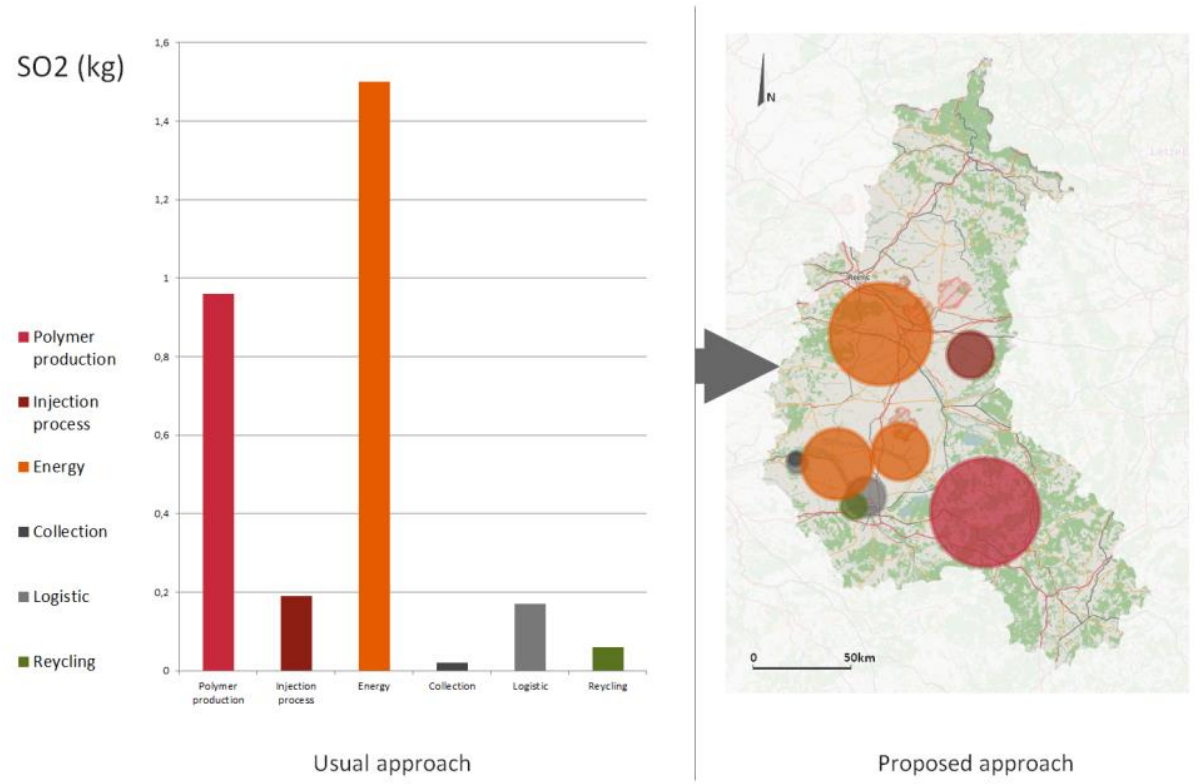

Fig. 4. Usual and proposed approach presentation on $\mathrm{SO} 2$ emission

Tackling the challenge of design for sustainability requires an integrated and systematic approach in order to understand the relation, for a specific territory, between designed products and their subsequent impact on the environment. The methodology presented in this paper is an attempt to provide such an approach by proposing a model linking product information and the impact on interacted territory based on a PEG system. Using different geographical data layers, this model can provide valuable information for decision makers. For instance, in the case study presented, $\mathrm{SO} 2$ emission is defined as a data layer illustrated on a map, which could be combined and compared with other data layers to predict future changes. In order to know if it is really applicable and of interest to decision makers, we have to: (1) complete case studies with other flows and geographical data layers in terms of substance flows under consideration; (2) put it into practice and evaluate the interest for decision makers and sustainability in design situations with students and professionals. 


\section{References}

1. Saaksvuori, A., Immonen, A.: Product lifecycle management. Springer Science \& Business Media (2008).

2. Vadoudi, K., Allais, R., Reyes, T., Troussier, N.: Sustainable Product Lifecycle Management and Territoriality: New structure for PLM. In: PLM International Conference. p. 10 (2014).

3. Vadoudi, K., Troussier, N.: A sustainable product model. DS 80-10 Proc. 20th Int. Conf. Eng. Des. (ICED 15) Vol 10 Des. Inf. Knowl. Manag. Milan, Italy, 27-30.07. 15. (2015).

4. Organization, I.S.: ISO 14040: Environmental Management-Life Cycle AssessmentPrinciples and Framework. (1997).

5. Zhang, Y., Luo, X., Buis, J.J., Sutherland, J.W.: LCA-oriented semantic representation for the product life cycle. J. Clean. Prod. 86, 146-162 (2015).

6. Fenves, S.J.: Core Product Model for Representing Design Information. Citeseer (2001).

7. Gujarathi, G.P., Ma, Y.-S.: Parametric CAD/CAE integration using a common data model. J. Manuf. Syst. 30, 118-132 (2011).

8. Roy, U., Sarigecili, M.I.: Information Models for Processing Product Lifecycle Functionalities and Interfaces for Sustainable Manufacturing. J. Comput. Inf. Sci. Eng. 16, 11005 (2016).

9. Samuel-Fitwi, B., Wuertz, S., Schroeder, J.P., Schulz, C.: Sustainability assessment tools to support aquaculture development. J. Clean. Prod. 32, 183-192 (2012).

10. Rodríguez, C., Ciroth, A., Srocka, M.: The importance of regionalized LCIA in agricultural LCA - new software implementation and case study. In: Proc. 9th Int. Conf. Life Cycle Assess Agri-Food Sector. San Francisco. pp. 1120-1128 (2014).

11. Mutel, C.L., Hellweg, S.: Regionalized life cycle assessment: computational methodology and application to inventory databases. Environ. Sci. Technol. 43, 5797-803 (2009).

12. Bartl, K., Verones, F., Hellweg, S.: Life cycle assessment based evaluation of regional impacts from agricultural production at the Peruvian coast. Environ. Sci. Technol. 46, 9872-80 (2012).

13. Mutel, C.L., Pfister, S., Hellweg, S.: GIS-based regionalized life cycle assessment: how big is small enough? Methodology and case study of electricity generation. Environ. Sci. Technol. 46, 1096-103 (2012).

14. Brentrup, F., Küsters, J., Kuhlmann, H., Lammel, J.: Environmental impact assessment of agricultural production systems using the life cycle assessment methodology. Eur. J. Agron. 20, 247-264 (2004)

15. Barbau, R., Krima, S., Rachuri, S., Narayanan, A., Fiorentini, X., Foufou, S., Sriram, R.D.: OntoSTEP: Enriching product model data using ontologies. Comput., 575-590 (2012).

16. Fiorentini, X., Gambino, I., Liang, V., Foufou, S., Rachuri, S., Bock, C., Mahesh, M.: Towards an ontology for open assembly model. In: International Conference on Product Lifecycle Management, Milan, Italy (2007).

17. Tursi, A., Panetto, H., Morel, G., Dassisti, M.: Ontological approach for products-centric information system interoperability in networked manufacturing enterprises. Annu. Rev. Control. 33, 238-245 (2009).

18. Rachuri, S., Baysal, M., Roy, U., Foufou, S., Bock, C., Fenves, S., Subrahmanian, E., Lyons, K., Sriram, R.: Information models for product representation: core and assembly models. Int. J. Prod. Dev. 2, 207-235 (2005).

19. Gruhier, E., Demoly, F., Dutartre, O., Abboudi, S., Gomes, S.: A formal ontology-based spatiotemporal mereotopology for integrated product design and assembly sequence planning. Adv. Eng. Informatics. 29, 495-512 (2015).

20. Chang, X.: Ontology Development and Utilization in Product Design, (2008).

21. Fortin, C., Huet, G.: Manufacturing Process Management: iterative synchronisation of engineering data with manufacturing realities. Int. J. Prod. Dev. 4, 280-295 (2007). 
22. Lee, J., Jeong, Y.: User-centric knowledge representations based on ontology for AEC design collaboration. Comput. Des. 44, 735-748 (2012).

23. Demoly, F., Monticolo, D., Eynard, B., Rivest, L., Gomes, S.: Multiple viewpoint modelling framework enabling integrated product-process design. Int. J. Interact. Des. Manuf. 4, 269-280 (2010).

24. Kim, K.-Y., Manley, D.G., Yang, H.: Ontology-based assembly design and information sharing for collaborative product development. Comput. Des. 38, 1233-1250 (2006).

25. Panetto, H., Dassisti, M., Tursi, A.: ONTO-PDM: product-driven ONTOlogy for Product Data Management interoperability within manufacturing process environment. Adv. Eng. Informatics. 26, 334-348 (2012).

26. Sudarsan, R., Fenves, S.J., Sriram, R.D., Wang, F.: A product information modeling framework for product lifecycle management. Comput. Des. 37, 1399-1411 (2005).

27. Cappellaro, F., Masoni, P., Moreno, A., Scalbi, S.: CASCADE. In: The 16th Internationale Conference: informatics for environment protection. pp. 490-493 (2002).

28. Bertin, B., Scuturici, V.-M., Risler, E., Pinon, J.-M.: A semantic approach to life cycle assessment applied on energy environmental impact data management. In: Proceedings of the 2012 Joint EDBT/ICDT Workshops. pp. 87-94. ACM (2012).

29. Takhom, A., Ikeda, M., Suntisrivaraporn, B., Supnithi, T., Hintemann, R., Fichter, K., Denward, M., De Jong, A., Olsen, R., Jakobi, T.: Toward Collaborative LCA Ontology Development: a Scenario-Based Recommender System. (2015).

30. Kosters, G., Pagel, B.-U., Six, H.-W.: GIS-application development with GeoOOA. Int. J. Geogr. Inf. Sci. 11, 307-335 (1997).

31. Hadzilacos, T., Tryfona, N.: An extended entity-relationship model for geographic applications. Acm Sigmod Rec. 26, 24-29 (1997).

32. Borges, K.A. V: Geographic data modeling-an extension of the OMT model for geographic applications. Esc. do Gov. MG/FJP. Belo Horizonte, Brazil. (1997).

33. Parent, C., Spaccapietra, S., Zimanyi, E., Donini, P., Plazanet, C., Vangenot, C.: Modeling spatial data in the MADS conceptual model. In: Proc. of the 8th Int. Symp. on Spatial Data Handling, SDH" 98 (1998).

34. Iochpe, C.: Specifying analysis patterns for geographic databases on the basis of a conceptual framework. In: Proceedings of the 7th ACM international symposium on Advances in geographic information systems. pp. 7-13. ACM (1999).

35. Pedersen, T.B., Tryfona, N.: Pre-aggregation in spatial data warehouses. In: SSTD. pp. 460-480. Springer (2001).

36. Malinowski, E., Zimányi, E.: Representing spatiality in a conceptual multidimensional model. In: Proceedings of the 12th annual ACM international workshop on Geographic information systems. pp. 12-22. ACM (2004).

37. GreenDeltaTC GmbH, Berlin, 2008: openLCA Framework - Modular Open Source Software for Sustainability Assessment - version $1-$, http://www. openlca.org.

38. Centre, E.C.J.R.: ILCD Handbook: General Guide for Life Cycle Assessment: Detailed Guidance. Publications Office of the European Union (2010).

39. Vadoudi, K., Kim, J., Laratte, B., Lee, S.-J., Troussier, N.: E-waste management and resources recovery in France. Waste Manag. Res. . (2015).

40. Weidema, B.P., Bauer, C., Hischier, R., Mutel, C., Nemecek, T., Reinhard, J., Vadenbo, C.O., Wernet, G.: Overview and methodology: Data quality guideline for the ecoinvent database version 3. Swiss Centre for Life Cycle Inventories (2013).

41. Selamat, M.H., Othman, M.S., Shamsuddin, N.H.M., Zukepli, N.I.M., Hassan, A.F.: A review on open source architecture in Geographical Information Systems. In: Computer \& Information Science (ICCIS), 2012 International Conference on. pp. 962-966. IEEE (2012).

42. Bivand, R.S., Pebesma, E., Gómez-Rubio, V.: Spatial Data Import and Export. Springer (2013). 